\title{
Infantile colic
}

\section{SUMMARY}

Infantile colic is a common, self-resolving condition. It has important adverse associations including maternal depression, child abuse and early cessation of breastfeeding.

There are many proposed causes of colic, however none is definitive. Colic is likely to be an exacerbation of normal infant crying brought about by physiological and psychosocial factors.

There is no known single effective treatment for colic. The mainstay of management is exclusion of organic causes, explanation of the natural history of colic, parental support, offering strategies to deal with the infant's feeding and sleep, and exploration of settling techniques.

The probiotic Lactobacillus reuteri DSM17938 may be trialled for exclusively breastfed infants with colic. Its efficacy in formula-fed babies is unknown.

An allergy to cow's milk protein accounts for a minority of cases. Hypoallergenic formula, and dietary exclusion for breastfeeding mothers, should only be tried in infants with other clinical features of cow's milk allergy.

\section{Introduction}

Infantile colic describes excessive crying of unknown cause in otherwise well infants. Colic affects up to $20 \%$ of infants,' and is one of the most common presentations to the primary health sector in early life. It resolves spontaneously after the first three to four months of life.

Colic is traditionally defined by the Wessel's criteria of crying or fussing more than three hours of the day for more than three days of the week. ${ }^{2}$ The new Rome IV criteria define it as 'recurrent and prolonged periods of infant crying, fussing or irritability reported by caregivers that occur without obvious cause and cannot be prevented or resolved'. ${ }^{3}$ The diagnosis can be assumed after exclusion of potential organic causes. Although colic is considered to be benign, it is a major burden to families, health professionals and the health system. Colic is strongly associated with maternal depression ${ }^{4}$ and is the strongest risk factor for shaken baby syndrome. ${ }^{5}$ It is also a common cause of early breastfeeding cessation. ${ }^{6}$ Crying beyond the usual colicky period can be linked to later sleep problems, allergic disorders, family dysfunction, and behavioural problems. ${ }^{7,8}$

\section{Causes of colic}

Despite years of research, the aetiology of colic remains elusive and there are many proposed theories. Does colic represent the most severe spectrum of normal infant distress, or is it a manifestation of underlying gastrointestinal, neurological or psychosocial disorders? Perhaps infant colic can be best regarded as an exacerbation of normal infant behaviour by a mixture of physiological and psychosocial factors. ${ }^{9}$

Colic should only be diagnosed after exclusion of organic causes. These occur in less than $10 \%$ of infants presenting with crying. ${ }^{10,11}$ Most organic causes present with other associated features (Table 1).

\section{Is it a gastrointestinal disorder?}

The word 'colic' implies an abdominal origin.

Postulated gastrointestinal mechanisms have included increased intraluminal gas, gut dysmotility, and visceral pain, but none is proven. ${ }^{12,13}$ Recent research has focused on the role of gut microbiota, with more than a dozen case-control studies suggesting that infants with colic may have differences in gut microbiota compared to those without colic. ${ }^{14,15}$ The majority of studies have found that Gram-negative organisms such as Escherichia species occur more frequently in colicky infants than in controls. Other studies have found fewer Lactobacillus species in those with colic. $^{14,15}$ In addition, some studies have suggested that infants with colic have increased gut and systemic inflammatory markers when compared to those without colic. ${ }^{16}$ However, the pathophysiological evidence for the role of gut microbiota and inflammation is still far from conclusive. ${ }^{17}$

\section{Gastro-oesophageal reflux}

Gastro-oesophageal reflux has been regarded as having a role in irritable infants, however anti-reflux medicines are ineffective in reducing crying. ${ }^{18,19}$ Studies have failed to show any correlation between

\section{Valerie Sung}

Paediatrician, Centre for Community Child Health and Department of General Medicine, Royal Children's Hospital

Early career research fellow, Murdoch Children's Research Institute

Senior honorary fellow, University of Melbourne Melbourne

\section{Keywords}

colic, breastfeeding, infant formula, probiotics

Aust Prescr 2018:41:105-10 https://doi.org/10.18773/ austprescr.2018.033 


\section{Table 1 Organic causes to exclude in a crying infant}

\begin{tabular}{|c|c|}
\hline Conditions to exclude & Additional clinical features \\
\hline \multirow[t]{6}{*}{ Cow's milk protein allergy } & Significant vomiting \\
\hline & Feeding difficulties \\
\hline & Diarrhoea with mucus or blood \\
\hline & Poor weight gain \\
\hline & Extensive eczema \\
\hline & First-degree family history of atopy \\
\hline \multirow[t]{4}{*}{ Gastro-oesophageal reflux disease } & Frequent significant vomiting (>5 times per day) \\
\hline & Haematemesis \\
\hline & Feeding difficulties \\
\hline & Poor weight gain \\
\hline Lactose intolerance or overload & Watery, frothy, explosive diarrhoea AND perianal excoriation or ulcerations \\
\hline \multirow[t]{2}{*}{ Inguinal hernia } & Vomiting \\
\hline & Lump in inguinal region \\
\hline \multirow[t]{2}{*}{ Intussusception } & Acute onset of vomiting, pallor, irritability \\
\hline & Abdominal mass, rectal bleeding \\
\hline \multirow{4}{*}{$\begin{array}{l}\text { Infection: urinary tract infection, } \\
\text { meningitis, otitis media }\end{array}$} & Fever \\
\hline & Lethargy \\
\hline & Poor feeding, poor weight gain \\
\hline & Perinatal risk factors for sepsis \\
\hline \multirow[t]{3}{*}{ Hydrocephalus } & Increasing head circumference/macrocephaly \\
\hline & Vomiting \\
\hline & Lethargy \\
\hline Hair tourniquet & Hair tourniquet around fingers or toes \\
\hline Foreign body in eye & Acute distress, history of foreign body penetration in eye \\
\hline \multirow[t]{2}{*}{ Non-accidental injury } & Bruising or petechiae \\
\hline & Other features of physical injury \\
\hline
\end{tabular}

pathological gastro-oesophageal reflux and crying in infants less than three months old. ${ }^{20}$ In the absence of frequent vomiting, haematemesis and poor weight gain, gastro-oesophageal reflux disease is an unlikely cause of infant crying. ${ }^{21}$

\section{Cow's milk protein allergy}

An allergy to cow's milk protein has been implicated as a cause of irritability, ${ }^{22,23}$ but accounts for probably less than $5 \%$ of cases of colic. ${ }^{24}$ It should be considered if the crying infant has feeding difficulties (during the day as well as at night), failure to thrive, significant vomiting, diarrhoea with mucus or blood, widespread eczema and a first-degree family history of atopy. The diagnosis can be confirmed if the symptoms resolve after excluding dairy food from the diet of breastfeeding mothers or using hypoallergenic formula (usually for a two-week trial period), together with reproduction of the symptoms on re-challenge with cow's milk protein.

\section{Lactose intolerance and overload}

Evidence for the role of lactose intolerance or overload in colic is mixed and inconclusive..$^{22,25-28}$ Lactose intolerance may be secondary to an underlying pathology such as cow's milk protein allergy or gastroenteritis. Lactose overload is usually a result of excessively frequent breastfeeding whereby the baby is snacking on the foremilk which has a high lactose content. Lactose intolerance or overload should be considered in the presence of watery, frothy, explosive diarrhoea with significant perianal excoriation or ulceration (due to acidic stools)

\section{Possible neurological or psychosocial causes}

Evidence for a neurological basis for colic is limited, ${ }^{29}$ although recent studies have suggested colic may be associated with both childhood migraine later on in life and migraines in the mother. ${ }^{30-32}$ Psychosocial factors such as infant temperament, mother-infant 
interactions, maternal anxiety and depression may be important contributors to colic. ${ }^{33,34}$ Maternal smoking may be a risk factor. ${ }^{35,36}$

\section{Management options}

Despite years of research, effective management options for colic are limited. Table 2 summarises the different proposed management options and the evidence for their effectiveness.

\section{Drug therapies}

Anticholinergic drugs, such as dicyclomine and cimetropium, reduce crying, ${ }^{37-40}$ but have potentially dangerous adverse effects, including drowsiness, apnoeas and coma. ${ }^{41}$ They are not recommended for infants younger than six months old. Despite its widespread use for colic, simethicone, an anti-foaming agent to reduce intraluminal gas, is not effective. ${ }^{37-40,42}$ Proton pump inhibitors are conclusively ineffective. ${ }^{18,19}$ Considering that there is increasing evidence of their association with adverse effects such as an increased risk of infections, ${ }^{43}$ they should not be routinely used for managing colic. There have been no studies examining the effect of gripe water on colic.

\section{Non-drug therapies}

Many natural remedies have been tried, but not rigorously studied. Few have evidence of effectiveness.

\section{Probiotics}

Recent evidence has emerged of a possible role for probiotics in infant colic. These are 'live microorganisms which, when administered in adequate amounts, confer a health benefit on the host'. ${ }^{44}$ Lactobacillus reuteri DSM17938 reduced infant crying in four double-blind randomised trials, two open-label and one single-blinded trial of exclusively breastfed infants with colic, at a dose of $1 \times 10^{8}$ colony-forming units per day. These studies all had sample sizes under $80.45-51$ In contrast, an Australian double-blind randomised trial, the largest to date $(n=167)$, including both breastfed and formula-fed infants with colic, concluded that $L$. reuteri was ineffective. ${ }^{52}$ The negative findings were replicated in a more recent smaller double-blind trial of 20 breastfed infants with colic..$^{53}$ In response to the conflicting results, a meta-analysis pooled raw data from four of the higher quality double-blind trials, involving 345 infants with colic (174 probiotic, 171 placebo). ${ }^{54}$ The reduction in daily crying from baseline to 21 days in the probiotic group was 25 minutes more than in the placebo group (adjusted mean difference in change from baseline $-25.4,95 \%$ confidence interval $(\mathrm{Cl})-47.3,-3.5)$. The probiotic group was more likely to experience treatment success (adjusted incidence ratio 1.7, $95 \% \mathrm{Cl} 1.4,2.2)$. Intervention effects were more
Table 2 Summary of evidence from randomised controlled trials for the management of colic

\begin{tabular}{ll}
\hline Effectiveness & Intervention \\
\hline $\begin{array}{l}\text { Effective for exclusively breastfed } \\
\text { infants with colic }\end{array}$ & Probiotic Lactobacillus reuteri DSM17938 \\
\hline Possibly effective & Hydrolysed formula \\
& Hypoallergenic diet in breastfeeding mothers \\
& Reduced stimulation \\
& Improved parental responsiveness \\
& Focused parent counselling \\
& Acupuncture \\
& Simethicone \\
& Spinal manipulation \\
& Lactase \\
Ineffective & Soy formula \\
& Fibre-enriched formula \\
& Carbohydrate alteration \\
Increased carrying \\
Car ride simulator \\
Crib vibrator \\
Dicyclomine, cimetropium \\
Herbal mixtures \\
Swaddling \\
Sucrose \\
\hline
\end{tabular}

pronounced in breastfed infants (number needed to treat $2.6,95 \% \mathrm{Cl} 2.0,3.6$ ). The meta-analysis of individual participant data concluded that $L$. reuteri DSM17938 was effective in exclusively breastfed infants with colic. There was insufficient evidence to make conclusions for formula-fed infants with colic. ${ }^{54}$

\section{Other non-drug therapies}

Next to L. reuteri, the best evidence for colic management is the use of hypoallergenic formulae or eliminating dairy foods from the diet of breastfeeding mothers. However, not all unsettled infants respond and most studies examining maternal elimination diets have methodological limitations. ${ }^{37-40,55,56}$ These approaches are probably only effective for babies who have an underlying allergy to cow's milk protein. ${ }^{56}$ Behavioural therapies such as reducing stimulation, improving parental responsiveness and parental counselling can be effective. However, the evidence comes from unblinded studies which are prone to bias. ${ }^{37-40}$

Acupuncture has been suggested to be effective in two recent studies, however there were methodological limitations in both. ${ }^{57,58} \mathrm{Herbal}$ mixtures given to infants with colic may be effective, ${ }^{59-62}$ 
however the consumption of large quantities of herbal teas has the potential to reduce milk intake and put infants at risk of nutritional deficiencies. ${ }^{39}$ Swaddling the baby may be effective, however there is concern that it can increase the risk of hip dysplasia. ${ }^{63,64}$ Sucrose is effective in reducing crying but its effects are short-lived. ${ }^{37-40}$ The use of lactase, soy or fibreenriched formulae, massage, music and spinal manipulation have all been shown to be ineffective for colic. ${ }^{37-40,65}$

\section{Recommendations}

The first step for managing colic is to exclude organic causes of crying by careful history and examination. Infants who have significant feeding difficulties and frequent vomiting, especially those who are struggling to gain weight, have a strong family history of allergy, and those with increasing irritability beyond three months should be considered for a limited trial of a hypoallergenic diet. Hypoallergenic formula or dietary elimination should only be continued if symptoms resolve and then reappear after a re-challenge with cow's milk protein.

It is important to explore the family's perceptions of their infant's crying, listen to their worries, acknowledge their feelings of anger, frustration and exhaustion, and avoid being dismissive of their concerns. Discussing the different hypotheses surrounding colic, and addressing each hypothesis in relation to the individual infant and family, can be helpful.

It is essential to screen for maternal postnatal depression and also pay attention to paternal wellbeing. Clinicians should explore parental coping mechanisms during times of extreme crying, explain the neurological consequences of shaken baby syndrome and suggest strategies to prevent it. All families should be offered support and help around the infant's feeding, settling, and sleep. Feeding difficulties must be addressed and managed. Strategies to soothe the infant should be explored, with recommendations to reduce environmental stimuli.
Families can often be reassured by understanding the self-resolving nature of colic, offering at least one review and more where necessary, putting in place strategies to increase emotional and social supports, and acknowledging that it may be difficult, if not impossible, to 'teach' their infant to 'self-soothe' during the first few months of life. Most of all, it is vital to recognise that the family is usually doing the best they can for their baby, to allay any feelings of failure or guilt, and to encourage them to take adequate breaks from their crying infant.

If the infant is exclusively breastfed, a three-week trial of the probiotic L. reuteri DSM17938 can be considered. It is important to discuss that even though the probiotic has been shown to be effective in breastfed babies in most trials across the world, it has not been shown to be effective in Australia and cannot be recommended for formula-fed infants. In addition, although the probiotic is considered safe without short-term adverse effects, its longer term effects are unknown.

\section{Conclusion}

The mainstay of management for colic is to help families cope with their infant's symptoms, reduce the risks of parental depression, child abuse and early breastfeeding cessation, and to prevent the possibility of long-term adverse effects. The myths surrounding colic should be explored, and the lack of evidence for any one effective intervention should be explained. All families must be offered strategies to manage their infant's feeding, settling and sleep, together with a recommendation to reduce environmental stimuli. Although evidence for these strategies is limited, they are not harmful or expensive. Other management strategies should be considered on a case-by-case basis suited to each individual family. $<$

Valerie Sung reports personal fees from Mead Johnson Nutrition for contributions to education materials.

\section{REFERENCES}

1. Lucassen PL, Assendelft WJ, van Eijk JT, Gubbels JW Douwes AC, van Geldrop WJ. Systematic review of the occurrence of infantile colic in the community. Arch Dis Child 2001;84:398-403. https://doi.org/10.1136/adc.84.5.398

2. Wessel MA, Cobb JC, Jackson EB, Harris Gs Jr, Detwiler AC. Paroxysmal fussing in infancy, sometimes called 'colic'. Pediatrics 1954;14:421-34.

3. Zeevenhooven J, Koppen IJN, Benninga MA. The new Rome IV criteria for functional gastrointestinal disorders in infants and toddlers. Pediatr Gastroenterol Hepatol Nutr 2017;20:1-13. https://doi.org/10.5223/pghn.2017.20.1.1

4. Vik T, Grote V, Escribano J, Socha J, Verduci E, Fritsch M, et al. Infantile colic, prolonged crying and maternal postnatal depression. Acta Paediatr 2009;98:1344-8. https://doi.org/ 10.1111/j.1651-2227.2009.01317.x

5. Barr RG. Preventing abusive head trauma resulting from a failure of normal interaction between infants and their caregivers. Proc Natl Acad Sci USA 2012;109 Suppl 2:17294-301. https://doi.org/10.1073/pnas.1121267109

6. Howard CR, Lanphear N, Lanphear BP, Eberly S, Lawrence RA. Parental responses to infant crying and colic: the effect on breastfeeding duration. Breastfeed Med 2006;1:146-55. https://doi.org/10.1089/bfm.2006.1.146

7. Savino F, Castagno E, Bretto R, Brondello C, Palumeri E, Oggero R. A prospective 10-year study on children who had severe infantile colic. Acta Paediatr Suppl 2005;94:129-32. https://doi.org/10.1111/j.1651-2227.2005.tb02169.x

8. Hemmi MH, Wolke D, Schneider S. Associations between problems with crying, sleeping and/or feeding in infancy and long-term behavioural outcomes in childhood: a metaanalysis. Arch Dis Child 2011;96:622-9. https://doi.org/10.1136/ adc. 2010.191312 
9. Barr RG. Colic and crying syndromes in infants. Pediatrics 1998;102(Suppl E):1282-6.

10. Gormally S, Barr R. Of clinical pies and clinical clues: proposal for a clinical approach to complaints of early crying and colic. Ambul Child Health 1997:3:137-53.

11. Freedman SB, Al-Harthy N, Thull-Freedman J. The crying infant: diagnostic testing and frequency of serious underlying disease. Pediatrics 2009;123:841-8. https://doi.org/ 10.1542/peds.2008-0113

12. Gupta SK. Is colic a gastrointestinal disorder? Curr Opin Pediatr 2002;14:588-92.

13. Geertsma MA, Hyams JS. Colic--a pain syndrome of infancy? Pediatr Clin North Am 1989:36:905-19. https://doi.org/10.1016/S0031-3955(16)36728-1

14. Sung V Cabana MD. Probiotics for colic: is the gut responsible for infant crying after all? J Pediatr 2017;191:6-8. https://doi.org/10.1016/j.jpeds.2017.09.010

15. Sung V, Pärtty A. Chapter 12 The association between intestinal microbiota and infant crying and behaviour. In: Browne PD, Claassen E, Cabana MD, editors. Microbiota in health and disease: from pregnancy to childhood. Wageningen, The Netherlands: Wageningen Academic Publishers; 2016. p. 219-43.

16. Pärtty A, Kalliomaki M, Salminen S, Isolauri E. Infantile colic is associated with low-grade systemic inflammation. J Pediatr Gastroenterol Nutr 2017;64:691-5. https://doi.org/ 10.1097/MPG.0000000000001340

17. de Weerth C, Fuentes S, de Vos WM. Crying in infants: on the possible role of intestinal microbiota in the development of colic. Gut Microbes 2013;4:416-21. https://doi.org/10.4161/ gmic. 26041

18. van der Pol RJ, Smits MJ, van Wijk MP, Omari TI, Tabbers MM, Benninga MA. Efficacy of proton-pump inhibitors in children with gastroesophageal reflux disease: a systematic review. Pediatrics 2011;127:925-35. https://doi.org/10.1542/ peds.2010-2719

19. Gieruszczak-Bialek D, Konarska Z, Skorka A, Vandenplas $Y$, Szajewska H. No effect of proton pump inhibitors on crying and irritability in infants: systematic review of randomized controlled trials. J Pediatr 2015;166:767-70.e3. https://doi.org/ 10.1016/j.jpeds.2014.11.030

20. Heine RG, Jaquiery A, Lubitz L, Cameron DJ, Catto-Smith AG. Role of gastro-oesophageal reflux in infant irritability Arch Dis Child 1995;73:121-5. https://doi.org/10.1136/adc.73.2.121

21. Heine RG, Jordan B, Lubitz L, Meehan M, Catto-Smith AG Clinical predictors of pathological gastro-oesophageal reflux in infants with persistent distress. J Paediatr Child Health 2006;42:134-9. https://doi.org/10.1111/j.1440-1754.2006.00812.x

22. Heine RG. Cow's-milk allergy and lactose malabsorption in infants with colic. J Pediatr Gastroenterol Nutr 2013:57:S25-S27. https://doi.org/10.1097/01.mpg.0000441930.13307.9b

23. Treem WR. Assessing crying complaints: the interaction with gastroesophageal reflux and cow's milk protein intolerance. In: Barr RG, St James-Roberts I, Keefe M, editors. New evidence on unexplained early infant crying: its origins, nature and management. Skillman, New Jersey: Johnson \& Johnson Pediatric Institute; 2001. p. 165-76.

24. Barr R, Geertsma M. Colic: the pain perplex. In: Schechter N, Berde C, Yaster M, editors. Pain in infants, children and adolescents. 2nd ed. Philadelphia: Lippincott Williams and Wilkins; 2003. p. 751-64.

25. Stahlberg MR, Savilahti E. Infantile colic and feeding Arch Dis Child 1986;61:1232-3. http://dx.doi.org/10.1136/ adc.61.12.1232

26. Miller JJ, McVeagh P, Fleet GH, Petocz P, Brand JC. Effect of yeast lactase enzyme on 'colic' in infants fed human milk. J Pediatr 1990;117:261-3. https://doi.org/10.1016/ S0022-3476(05)80542-6

27. Kanabar D, Randhawa M, Clayton P. Improvement of symptoms in infant colic following reduction of lactose load with lactase. J Hum Nutr Diet 2001;14:359-63. https://doi.org/10.1046/j.1365-277X.2001.00304.x

28. Kearney PJ, Malone AJ, Hayes T, Cole M, Hyland M. A trial of lactase in the management of infant colic. J Hum Nutr Diet 1998;11:281-5. https://doi.org/10.1046/ j.1365-277X.1998.00108.x

29. Kirjavainen J, Jahnukainen T, Huhtala V, Lehtonen L, Kirjavainen $\mathrm{T}$, Korvenranta $\mathrm{H}$, et al. The balance of the autonomic nervous system is normal in colicky infants. Acta Paediatr 2001;90:250-4. https://doi.org/10.1111/ j.1651-2227.2001.tb00299.x
30. Romanello S, Spiri D, Marcuzzi E, Zanin A, Boizeau P, Riviere S, et al. Association between childhood migraine and history of infantile colic. JAMA 2013;309:1607-12. https://doi.org/10.1001/jama.2013.747

31. Qubty W, Gelfand AA. The link between infantile colic and migraine. Curr Pain Headache Rep 2016;20:31 https://doi.org/10.1007/s11916-016-0558-8

32. Gelfand AA, Goadsby PJ, Allen IE. The relationship between migraine and infant colic: a systematic review and meta-analysis. Cephalalgia 2015;35:63-72. https://doi.org/10.1177/0333102414534326

33. Hiscock H, Jordan B. Problem crying in infancy. Med J Aust 2004;181:507-12.

34. Raiha H, Lehtonen L, Huhtala V, Saleva K, Korvenranta H. Excessively crying infant in the family: mother-infant, father-infant and mother-father interaction. Child Care Health Dev 2002;28:419-29. https://doi.org/ 10.1046/j.1365-2214.2002.00292.x

35. Canivet CA, Ostergren PO, Jakobsson IL, Dejin-Karlsson E, Hagander BM. Infantile colic, maternal smoking and infant feeding at 5 weeks of age. Scand J Public Health 2008:36:284-91. https://doi.org/10.1177/1403494807086981

36. Shenassa ED, Brown MJ. Maternal smoking and infantile gastrointestinal dysregulation: the case of colic. Pediatrics 2004;114:e497-505. https://doi.org/10.1542/peds.2004-1036

37. Hall B, Chesters J, Robinson A. Infantile colic: a systematic review of medical and conventional therapies. J Paediatr Child Health 2012;48:128-37. https://doi.org/ 10.1111/j.1440-1754.2011.02061.x

38. Cohen-Silver J, Ratnapalan S. Management of infantile colic: a review. Clinical Pediatrics 2009;48:14-7. https://doi.org/10.1177/0009922808323116

39. Garrison MM, Christakis DA. A systematic review of treatments for infant colic. Pediatrics 2000;106:184-90.

40. Lucassen PLBJ, Assendelft WJJ, Gubbels JW, van Eijk JTM, van Geldrop WJ, Neven AK. Effectiveness of treatments for infantile colic: systematic review. BMJ 1998;316:1563-9. https://doi.org/10.1136/bmj.316.7144.1563

41. Williams J, Watkins-Jones R. Dicyclomine: worrying symptoms associated with its use in some small babies. Br Med J (Clin Res Ed) 1984;288:901. https://doi.org/10.1136/ bmj.288.6421.901

42. Metcalf TJ, Irons TG, Sher LD, Young PC. Simethicone in the treatment of infant colic: a randomized, placebo-controlled, multicenter trial. Pediatrics 1994;94:29-34

43. Canani RB, Cirillo P, Roggero P, Romano C, Malamisura B, Terrin $G$, et al. Therapy with gastric acidity inhibitors increases the risk of acute gastroenteritis and communityacquired pneumonia in children. Pediatrics 2006;117:e817-20. https://doi.org/10.1542/peds.2005-1655

44. Probiotics in food: health and nutritional properties and guidelines for evaluation. FAO Food and Nutrition Paper 85. Rome: Food and Agriculture Organization of the United Nations and World Health Organization; 2006. http://www.fao.org/publications/card/en/c/7c102d95-2fd55b22-8faf-f0b2e68dfbb6 [cited $2018 \mathrm{Jul} 1$ 1]

45. Chau K, Lau E, Greenberg S, Jacobson S, Yazdani-Brojeni P, Verma N, et al. Probiotics for infantile colic: a randomized, double-blind, placebo-controlled trial investigating Lactobacillus reuteri DSM 17938. J Pediatr 2015;166:74-8. https://doi.org/10.1016/j.jpeds.2014.09.020

46. Savino F, Cordisco L, Tarasco V, Palumeri E, Calabrese R, Oggero R, et al. Lactobacillus reuteri DSM 17938 in infantile colic: a randomized, double-blind, placebo-controlled trial. Pediatrics 2010;126:e526-33. https://doi.org/10.1542/ peds.2010-0433

47. Savino F, Pelle E, Palumeri E, Oggero R, Miniero R. Lactobacillus reuteri (American Type Culture Collection Strain 55730) versus simethicone in the treatment of infantile colic: a prospective randomized study. Pediatrics 2007;119:e124-30. https://doi.org/10.1542/peds.2006-1222

48. Szajewska H, Gyrczuk E, Horvath A. Lactobacillus reuteri DSM 17938 for the management of infantile colic in breastfed infants: a randomized, double-blind, placebo-controlled trial. J Pediatr 2013;162:257-62. https://doi.org/10.1016/ j.jpeds.2012.08.004

49. Mi GL, Zhao L, Qiao DD, Kang WQ, Tang MQ, Xu JK. Effectiveness of Lactobacillus reuteri in infantile colic and colicky induced maternal depression: a prospective single blind randomized trial. Antonie Van Leeuwenhoek 2015;107:1547-53. https://doi.org/10.1007/s10482-015-0448-9 
50. Savino F, Garro M, Montanari P, Galliano I, Bergallo M. Crying time and RORg/FOXP3 expression in Lactobacillus reuteri DSM17938-treated infants with colic: a randomized trial. J Pediatr 2018;192:171-7.e1. https://doi.org/10.1016/ j.jpeds.2017.08.062

51. Ashraf MW, Ayaz SB, Ashraf MN, Matee S, Shoaib M. Probiotics are effective in alleviating infantile colic: results of a randomized controlled trial held at Benazir Bhutto Hospital, Rawalpindi, Pakistan. Rawal Med J 2015;40:277-80. https://www.rmj.org.pk/?mno=177300 [cited 2018 Jul 1]

52. Sung V, Hiscock H, Tang M, Mensah FK, Nation ML, Satzke C et al. Treating infant colic with the probiotic Lactobacillus reuteri: double-blind, placebo-controlled randomised trial. BMJ 2014;34:g2107. https://doi.org/10.1136/bmj.g2107

53. Fatheree NY, Liu Y, Taylor CM, Hoang TK, Cai C, Rahbar MH, et al. Lactobacillus reuteri for infants with colic: a doubleblind, placebo-controlled, randomized clinical trial. J Pediatr 2017;191:170-8.e2. https://doi.org/10.1016/ j.jpeds.2017.07.036

54. Sung V, D'Amico F, Cabana M, Chau K, Koren G, Savino F, et al. Lactobacillus reuteri to treat infant colic: a metaanalysis. Pediatrics 2018;141:e20171811. https://doi.org/ 10.1542/peds.2017-1811

55. lacovou M, Ralston RA, Muir J, Walker KZ, Truby H. Dietary management of infantile colic: a systematic review. Matern Child Health J 2012;16:1319-31. https://doi.org/ 10.1007/s10995-011-0842-5

56. Nocerino R, Pezzella V, Cosenza L, Amoroso A, Di Scala C Amato $F$, et al. The controversial role of food allergy in infantile colic: evidence and clinical management. Nutrients 2015;7:2015-25. https://dx.doi.org/10.3390/nu7032015

57. Landgren K, Kvorning N, Hallstrom I. Acupuncture reduces crying in infants with infantile colic: a randomised, controlled, blind clinical study. Acupuncture Med 2010;28:174-9. https://dx.doi.org/10.1136/aim.2010.002394
58. Reinthal M, Andersson S, Gustafsson M, Plos K, Lund I, Lundeberg $\mathrm{T}$, et al. Effects of minimal acupuncture in children with infantile colic: a prospective, quasi-randomised single blind controlled trial. Acupunct Med 2008;26:171-82. http://dx.doi.org/10.1136/aim.26.3.171

59. Martinelli M, Ummarino D, Giugliano FP, Sciorio E, Tortora C, Bruzzese D, et al. Efficacy of a standardized extract of Matricariae chamomilla L., Melissa officinalis L. and tyndallized Lactobacillus acidophilus (HA122) in infantile colic: an open randomized controlled trial. Neurogastroenterol Motil 2017;29. Epub 2017 Jun 30. https://doi.org/10.1111/nmo.13145

60. Savino F, Cresi F, Castagno E, Silvestro L, Oggero R. A randomized double-blind placebo-controlled trial of a standardized extract of Matricariae recutita, Foeniculum vulgare and Melissa officinalis (ColiMil) in the treatment of breastfed colicky infants. Phytother Res 2005;19:335-40. https://doi.org/10.1002/ptr.1668

61. Alexandrovich I, Rakovitskaya O, Kolmo E, Sidorova T, Shushunov S. The effect of fennel (Foeniculum vulgare) seed oil emulsion in infantile colic: a randomized, placebocontrolled study. Altern Ther Health Med 2003;9:58-61.

62. Weizman Z, Alkrinawi S, Goldfarb D, Bitran C. Efficacy of herbal tea preparation in infantile colic. J Pediatr 1993;122:650-2. https://doi.org/10.1016/S0022-3476(05)83557-7

63. van Sleuwen BE, Engelberts AC, Boere-Boonekamp MM, Kuis W, Schulpen TW, L'Hoir MP. Swaddling: a systematic review. Pediatrics 2007:120:e1097-106. https://doi.org/ 10.1542/peds.2006-2083

64. Clarke N. Swaddling and hip dysplasia: an orthopaedic perspective. Arch Dis Child 2014;99:5-6. https://doi.org/ 10.1136/archdischild-2013-304143

65. Dobson D, Lucassen PL, Miller JJ, Vlieger AM, Prescott $P$ Lewith G. Manipulative therapies for infantile colic. Cochrane Database Syst Rev 2012:CD004796. https://doi.org/10.1002/14651858.CD004796.pub2 